\title{
Article
}

\section{The role of motion analysis in elite soccer}

Carling, C., Bloomfield, J., Nelsen, L., and Reilly, T.

Available at http://clok.uclan.ac.uk/12265/

Carling, C. ORCID: 0000-0002-7456-3493, Bloomfield, J., Nelsen, L., and Reilly, T. (2008) The role of motion analysis in elite soccer. Sports Medicine, 38 (10). pp. 839-862. ISSN 0112-1642

It is advisable to refer to the publisher's version if you intend to cite from the work. http://dx.doi.org/10.2165/00007256-200838100-00004

For more information about UCLan's research in this area go to http://www.uclan.ac.uk/researchgroups/ and search for < name of research Group>.

For information about Research generally at UCLan please go to http://www.uclan.ac.uk/research/

All outputs in CLoK are protected by Intellectual Property Rights law, including Copyright law. Copyright, IPR and Moral Rights for the works on this site are retained by the individual authors and/or other copyright owners. Terms and conditions for use of this material are defined in the policies page.

\section{CLoK}

Central Lancashire online Knowledge www.clok.uclan.ac.uk

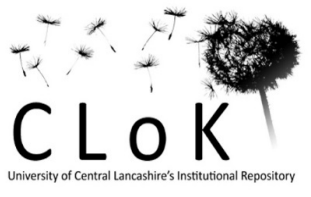


This is a pre-proof corrected manuscript, as accepted for publication, of an article published by Springer International Publishing in Sports Medicine in October 2008. The final publication is available at link.springer.com:

http://link.springer.com/article/10.2165/00007256-200838100-00004

\section{PLEASE REFER TO THE PUBLISHED VERSION FOR CITING PURPOSES}

9 The role of motion analysis in elite soccer

10

11 Christopher Carling ${ }^{1}$, Jonathan Bloomfield ${ }^{2}$, Lee Nelsen ${ }^{3}$, Thomas Reilly ${ }^{4}$

${ }^{1}$ LOSC Lille Métropole Football Club, Centre de Formation, Stadium Lille Métropole 30 Av. de la Chatellenie, 59650 Villeneuve d'Ascq, France

${ }^{2}$ Sports Institute of Northern Ireland, University of Ulster, Jordanstown, Northern Ireland, $B T 370 Q B, U K$

${ }^{3}$ School of Sport and Exercise Sciences, Loughborough University, Leicestershire, LE11 $3 T U, U K$

${ }^{4}$ Research Institute for Sport and Exercise Sciences, Liverpool John Moores University,

24 Phone: 00.33.1.48910793

25 Fax: 00.33.1.48910793

26 Email: chris.carling@free.fr 


\section{Abstract}

2 The optimal physical preparation of elite soccer (association football) players has

3 become an indispensable part of the professional game especially due to the increased

4 physical demands of match-play. The monitoring of players' work-rate profiles during

5 competition is now feasible through computer-aided motion analysis. Traditional methods of

6 motion analysis were extremely labour intensive and were largely restricted to university-

7 based research projects. Recent technological developments have meant that sophisticated

8 systems, capable of quickly recording and processing the data of all players' physical

9 contributions throughout an entire match, are now being used in elite club environments. In

10 recognition of the important role motion analysis now plays as a tool for measuring the

11 physical performance of soccer players, this review critically appraises various motion

12 analysis methods currently employed in elite soccer and explores research conducted using

13 these methods. This review therefore aims to increase the awareness of both practitioners and

14 researchers of the various motion analysis systems available, identify practical implications of

15 the established body of knowledge, while highlighting areas that require further exploration.

16

17 Key terms: fatigue, global positioning systems, match analysis, positional role 
A significant body of research into the host of factors contributing towards optimal

3 performance in sport has emerged over the past two decades. ${ }^{[1]}$ This increased research

4 activity has been particularly evident in soccer (association football), where the importance of

5 scientific research and applied work has become increasingly accepted in the professional

6 game. ${ }^{[2]}$ Over this period, comprehensive reviews have been published on the physiology, ${ }^{[3,4]}$

7 psychology, ${ }^{[1,5]}$ biomechanics ${ }^{[6]}$ and interdisciplinary ${ }^{[7]}$ aspects of soccer. This growing

8 acceptance of sports science is unsurprising considering the performance-enhancing role that

9 it can offer elite soccer coaches continually searching for a competitive edge against rival 10 teams. $^{[8]}$

Among the traditional sport science disciplines, exercise physiology has arguably had the greatest impact upon practices within professional soccer. The optimisation of physical fitness is now an integral facet of player and team preparation. Physiological demands of contemporary professional soccer implicate an increased work-rate, a higher frequency of competition, and as a consequence, players are obliged to work harder than in previous decades. ${ }^{[9,10]}$ The monitoring of players' work-rate profiles during competition was originally achieved using manual video-based motion analysis techniques such as that developed by Reilly and Thomas. ${ }^{[1]}$ The employment of such methods elicited essential scientific observations but the perceived complexity and consumption of time required for coding, analysing and interpreting the output formed barriers to their adoption by performance analysts. ${ }^{[12]}$ The original techniques were also extremely time-consuming and restricted to the analysis of a single player and therefore were limited to university based research projects.

Over the past decade, technological advances have included the introduction of increasingly sophisticated motion analysis systems that have begun to be utilised in elite 
1 relatively short period of time, and provide a valuable pool of data that can inform and

2 influence the daily practices of coaches. The utilisation of these advanced approaches furthers

3 our understanding of position-specific work-rate profiles of soccer players and their fitness

4 requirements, the intensities of discrete activities during match play and the occurrence of a

5 reduced work-rate among players. ${ }^{[13,14]}$ Moreover, these contemporary methods employed by

6 elite clubs can be used to make objective decisions for structuring the conditioning elements

7 of training and subsequent match preparation.

In recognition of the important role that motion analysis now plays as a tool for

9 measuring the physical performance of soccer players, we begin by critically appraising the

10 various methods of motion analysis available to researchers and practitioners in soccer.

11 Throughout, we highlight that many of the latest computerised systems now are not only logistically practical, but also offer a greater breadth of analysis when compared to the more traditional labour-intensive methods. However, many of these systems still require scientific validation to ensure that data derived from these methods are both accurate and reliable. A presentation and critical appraisal of various validation protocols used for assessing contemporary motion analysis technologies are provided in an attempt to prompt further research into this area of investigation. Also considered are various issues concerning the interpretation of the data obtained through techniques of motion-analysis. In the remainder of this review, motion analysis research into work-rate profiles within competitive games, exercise patterns, positional demands, fatigue and other uses, is considered. Collectively this review should serve to increase awareness of practitioners and researchers concerning the various motion analysis systems and the body of accumulated knowledge acquired through using this approach, whilst identifying areas that require further exploration.

\section{Contemporary techniques for work-rate analysis}


$2 \quad 1.1$ Individual player analysis

Motion analysis has been applied for over 30 years to the study of work-rates in

4 professional soccer, since the classical study of Reilly and Thomas ${ }^{[1]}$. Research studies

5 undertaken in the last 5 years by Scandinavian and Italian researchers ${ }^{[15-19]}$ on top-level soccer

6 have incorporated similar approaches to that employed over a decade earlier by Bangsbo and

7 co-workers ${ }^{[20]}$. This original method involved the positioning of video cameras near the side of

8 the pitch, at the level of the midfield line, at a height of approximately $15 \mathrm{~m}$ and at a distance

9 of 30-40 m from the touchline. Each camera was used to film a separate player. After the game, the subjects were video-taped for reference purposes whilst performing specific activities from walking to sprinting in order to provide calibration values. The video tapes were played back on a television monitor and coded for various match activities. The duration of each activity was recorded, total time summed and frequency of activity calculated according to separate time blocks. The distance covered at each activity within each time block was the product of mean velocity and total time spent in the activity. The total distance covered during a match was calculated as the sum of the distances covered during each individual type of locomotor activity.

The main technological advancement evident in subsequent studies has been the employment of better quality cameras and more advanced input coding methods as a result of 20 contemporary computer software. To this end, Bloomfield et al. ${ }^{[21]}$ used the "PlayerCam" 21 facility (Sky Sports Interactive Service, British Sky Broadcasting Group, UK) to provide high-quality close-up video footage focusing on a single player's movements and actions. The footage was digitised and synchronised for manual coding using the Noldus Observer Pro 24 behavioural analysis system ${ }^{[22]}$ which in turn automatically calculated the time spent in the defined movement activities. 
These particular video-based methods used for manually measuring work-rates have

2 generally demonstrated in the studies that have been reported to use them, high levels of 3 reliability, objectivity and validity. ${ }^{[8]}$ For example, a previous report that employed these

4 methods, stated that no systematic differences were reported in a test-retest analysis of a 5 match and the mean intra-individual difference in total distance covered was less than $0.2 \mathrm{~km}$

6 (coefficient of variation, $\mathrm{CV}=1 \%) .{ }^{[15]}$ Nevertheless, human error is possible in entering data

7 inaccurately due to the subjective nature of human movement recognition, variable observer 8 reaction to events being performed by the player under scrutiny and different interpretations 9 of performance indicators relating to work-rate and movement by different observers. ${ }^{[23]}$ In addition, the methods previously described are restricted to the filming and analysis of a single player per camera. Video-based motion analysis may also be subject to errors due to changes in gait during game movements, ${ }^{[24]}$ and provides only low spatial and temporal 13 resolutions. ${ }^{[25]}$ Furthermore, these techniques do not allow real-time analysis and are extremely labour-intensive in terms of the capture and analysis of data. In this respect, the detailed manual methodology used by Bloomfield et al. ${ }^{[26]}$ to code manually and determine the physical demands of English Premier League football was described by the authors as extremely time consuming and laborious. This criticism applied even for the collection of data from only $5 \mathrm{~min}$ of match footage due to the frequent changes of movement type, direction and/or intensity. A total of 1,563 'purposeful movement' passages were observed for 55 players during 15-min periods of Premier League soccer which involved 23,487 changes in movement, direction, perceived intensity or individual soccer-specific events (e.g. pass, dribble, shoot). Players performed a mean of $28.4 \pm 4.3$ passages of purposeful movement for each 15-min period of the match at a mean duration of $13.1 \pm 3.2 \mathrm{~s}$. These figures equate to a mean of 15.03 changes in activity for each passage at a rate of 0.87 per second. No significant differences were found between the amount of purposeful movement passages by match 
1 period or playing position although strikers had a significantly shorter mean duration and

2 frequency of passages $>15 \mathrm{~s}$. Due to the level of detail in this manual based time-motion 3 analysis, the application and use of such methods of motion analysis are generally restricted

4 to academic research projects as the intense competitive schedules of elite soccer clubs 5 require data to be available usually within 24-36 hours post-match. The difficulties 6 encountered in manually coding movements may lead some researchers to analyse a single 7 selected period of action per player per game. Attempts can then be made to extrapolate the data from these periods to a projection for the entire match. However, incomplete recordings are limited in their ability to provide detailed individual work-rates as the work-rate pattern is highly variable throughout a game and is therefore not so easily predictable. ${ }^{[27]}$

As technology has advanced, time-motion analysis has begun to incorporate electronic devices, mathematical modelling procedures for automatic tracking, sophisticated computer processes and satellite tracking. An overview of contemporary systems used to analyse workload in soccer can be seen in Table I.

Many contemporary approaches are based essentially on an original method designed by Ohashi et al. ${ }^{[28]}$ which employed the calculation of players' position and speed through trigonometric techniques. For example, the motion characteristics of elite Japanese soccer players have been recently measured throughout a game's entirety using a triangular 19 surveying method. ${ }^{[29]}$ This method entailed recording the player's movement as angular changes, which were measured by two potentiometers linked to cameras mounted outside and overlooking the field of play. Coordinates for the player were calculated using the angular data from the cameras and were monitored every 0.5 seconds. The distance between two consecutive coordinates was calculated continuously to obtain the total distance covered. The major limitation of this particular methodology was that it did not allow simultaneous analyses of more than one player. ${ }^{[8]}$ Limiting the analysis of the activity profile to one player 
1 per game does not allow comparisons to be drawn between the concomitant work-rate profiles

2 of team-mates or those of opposing players and can limit full understanding of the tactical

3 importance of work-rate. ${ }^{[27]}$

A further technological advancement in this field has been the development of the software "Trakperformance" which provides a means of mechanically following a single

6 player using a conventional computer pen and commercially available drawing tablet on a

7 scaled version of the specific playing field. ${ }^{[24,30]}$ This method is an improvement from the 8 classical cartographic approach previously used by Japanese researchers where movements of 9 soccer players were traced onto a scaled map of the pitch presented on paper sheets. ${ }^{[31]}$ The Trakperformance system functions by using ground markings around the pitch which are employed as reference points for tracking the players. The miniaturised playing field is calibrated so that a given movement of the mouse or mouse-pen corresponds to the linear distance travelled by the player. This computerised system has demonstrated acceptable levels of accuracy and intra- and inter- observer reliability. For example, an error measurement level of $5 \%$ for player distances has been presented and a test of inter-observer reliability between three separate observers reported a Pearson's correlation of $r=0.98$ for total distance travelled. ${ }^{[30]}$ A further advantage is that movements can also be tracked in real-time (although operator skill does need to be very high and a sustained training period is needed for familiarisation with the technique) and cost is significantly reduced in comparison to other commercially available tracking systems. Finally, the portability of this system means it can be readily employed to analyse work-rates of players within training contexts.

24 Few systems have the ability to analyse all the players in a team throughout a whole match, tracking each player both on and off the ball. ${ }^{[32]}$ The AMISCO Pro system developed in the 
1 late 1990s by Sport-Universal Process in collaboration with the French Football Federation

2 was the first system to achieve the simultaneous analysis of the work-rate of every player in a

3 team throughout the entirety of a match. ${ }^{33}$ This system measures the movements on video, of

4 every player, the referee and ball by sampling activity up to twenty-five times a second during

5 the whole game. ${ }^{[8,34]}$ This process leads to the collection of around 4.5 million data-points for 6 position on the pitch as well as over 2000 ball touches per match. Along with the ProZone ${ }^{\circledR}$

7 system, ${ }^{[35,36]}$ its chief commercial European competitor, these pioneer multi-player video 8 tracking systems based on state-of-the-art computer and video technology are currently the 9 most comprehensive and widely used commercial tracking systems in professional European soccer. These systems provide a detailed analysis of each player's work-rates over the entire match, and create a two-dimensional animated reconstruction of player movements together with an interactive graphical representation of all playing actions such as passes and duels. ${ }^{[37]}$ Video-based multi-player tracking systems such as AMISCO Pro and ProZone generally require the permanent installation of several cameras fixed in optimally calculated positions to cover the entire surface of play (Figure 1). This lay-out ensures that every player is captured on video, whatever the position and the moment in time. The number, position, orientation, zoom and field of vision of the cameras depend on factors such as the dimensions of the pitch and the structure of the stadium. The stadium and pitch are calibrated in terms of height, length and width and transformed into a two-dimensional model to allow player positions (x, y coordinates) to be calculated from the camera sources. Complex trigonometry, propriety mathematical algorithms, image-object transformation methods for obtaining 2-D or 3-D space coordinates such as Direct Linear Transformation (DLT) ${ }^{[38]}$ from video footage of 23 soccer play, as well as various image processing and filtering techniques, can be used to identify each player's location on the pitch. The individual's movements can then be tracked on the video by computer software through either manual operation or automatic tracking 
1 processes, at every single moment of the game. The technology is facilitated by supportive

2 information such as shirt colour, optical character recognition of shirt numbers and prediction

3 of running patterns to help maintain accurate player identification and tracking. During set-

4 play actions such as corners or free- kicks, play can become compressed so such supportive

5 information may be required to help maintain accuracy in tracking individual players. For a

6 further description of the workings of video-based player tracking, see Di Salvo et al. ${ }^{[35]}$ and

7 Barros et al. ${ }^{[25]}$

Despite being largely computer automated, these pioneer tracking systems still require some manual input as well as continual verification by an operator to make sure that players are correctly tracked by the computer program. Automatic tracking may not be possible due to changes in light quality as well as occlusions due to a crowd of players gathering in a small zone at one time. In this case, it becomes necessary for an operator to correct these mistakes manually. Nevertheless, the Dvideo system designed at the University of Campinus, Brazil, is reported to have a $95 \%$ automatic tracking rate. ${ }^{[25]}$ However, this system used a lower number of digital film images per second (7.5 hertz) compared to other video tracking systems such as AMISCO Pro in order to reduce the amount of data to be processed. This footage would lower its capacity to measure in detail, changes in running speed and direction. Work has also shown when determining the positions of soccer player from digital video footage that a low frequency images per second ( $2 \mathrm{~Hz}$ for example) may lead to a higher rate of error when

20 calculating distances covered. ${ }^{[39]}$ A recent DLT-based video-tracking system used to analyse the work-rates of professional Japanese players reportedly requires the utilisation of a single digital camcorder, making it more cost effective in comparison to multi-camera systems. ${ }^{[40]}$

23 However, it also employs a limited number of image frames per second $(2 \mathrm{~Hz})$ and requires manual frame-by-frame analysis of play. Furthermore, no information is available on the time required to analyse physical performance using this system and its reliability has not been 
1 investigated. Most of these video tracking systems used to date in elite soccer do not provide

2 real-time analysis, the results generally being available within 24-36 hours of the final

3 whistle. This time lag, however, seems acceptable for the many top-level clubs who have

4 adopted these systems over the last decade.

The most recent commercial video-based automatic tracking systems such as

6 DatatraX $^{[41]}$ and the TRACAB Image Tracking System ${ }^{[42]}$ now provide real-time analysis albeit using similar tracking methodologies based on multi-camera and image processing techniques. According to commercial information available from the supplier, ${ }^{[42]}$ the TRACAB system exploits enhanced techniques for video image processing and by using mathematical algorithms designed for object tracking and guiding missiles in the military industry. Similarly, DatatraX uses pixel recognition to track the players automatically and voice recognition to code the match specific events. Three manual operators are required to manage the process, two people to correct tracking mistakes in real-time for each team and one to perform the voice recognition coding procedure. The main benefit of both systems is that they provide coaches with a high level of instantly available detail concerning match performance, allowing informed decisions to be made during the match that may influence the eventual outcome. Although both companies claim to have high levels of accuracy for their systems, the validity and reliability have again yet to be scientifically established. material is strictly forbidden by various governing bodies of soccer. Their major disadvantage, however, resides in the high costs and the necessity of installing multiple cameras and a computerised network with at least one dedicated operator to organise the data collection and further operators to perform the analysis. ${ }^{[35]}$ This apparent lack of portability 
1 However, the DatatraX system can apparently still be operated at away venues using two

2 portable cameras from the stadium gantry and some mathematical corrections for errors 3 created when players are further away from the camera lens. In addition, the introduction of 4 reciprocal contractual agreements has led to clubs being able to access work-rate data when 5 playing in opposition stadia which also equipped with their same service providers system. Electronic transmitting devices have previously been described as the future of the computerised analysis of sport and are taking match analysis one step further in terms of data 8 processing speed and accuracy. ${ }^{[8]}$ These wireless and telemetric communication systems allow 9 remote real-time data acquisition and record movements and positions of every player and the ball up to several hundreds times per second. A small lightweight microchip transmitter is worn in clothing or in a strap around the chest of each player. The identification signal of the transmitter is registered in a fraction of a second by several antennae positioned around and outside the playing field. The reception time of the signal source to the recipient is synchronised and as a result the position is determined. These data are relayed to a central computer and immediately processed for immediate analysis. The LPM Soccer 3D® system developed by INMOTIO in collaboration with PSV Eindhoven Football Club provides positional measurements over a 100 times per second leading to the production of highly detailed and previously unavailable information on player accelerations, decelerations and changes in direction. ${ }^{[43]}$ This system also combines physical data with physiological measurements through heart-rate monitoring (built into the transmitter) as well as

21 synchronised video footage to provide a comprehensive picture of the daily, weekly and monthly workloads experienced in training. Constraints of such systems include potential electronic interference, strength of the electronic signals from players due to the size of 24 playing surfaces and the energy source to accomplish this signal transfer. ${ }^{[24]}$ Furthermore, no 
1 investigation has yet attempted to determine scientifically the reliability of these electronic measuring systems.

Global Positioning Technology (GPS) has also begun to impact on the analysis of performance in elite soccer. As with electronic transmitting devices, its use is restricted to measuring player efforts during training sessions or friendly matches although it is now permitted in competition for other codes of professional football such as Australian Rules Football. The technology of GPS requires a receiver to be worn by each athlete which draws on signals sent from at least four earth orbiting satellites to determine positional information and calculate movement speeds, distances and pathways as well as altitude. ${ }^{[4]}$ The latest SPI Elite GPS receiver designed by GPSports has been adopted by several teams competing in the English Premier Football League and is provided with propriety software for simultaneous analysis of data from all players. ${ }^{[45]}$ Similarly, in Spain a company known as Real Track Football has also made commercial GPS systems specifically available for soccer teams. ${ }^{[46]}$ It is possible to purchase kits with over 11 trackers in a set, with potential applications to training contexts and to the other football codes.

Although automatic tracking devices have established methods of providing data on work-rate characteristics such as total distance run and time spent in various categories of movement, the latest systems are advancing the analysis of sports performance through a superior level of co-ordinated biofeedback to accompany the traditional physical feedback. In this respect, the SPI Elite GPS is capable of monitoring heart rate and recording information on the frequency and intensity of impacts such as tackles and collisions by means of a built in tri-axis accelerometer which also depicts three direction types (forwards, sideways and backwards). The accuracy and reliability of GPS receivers are relatively high as results of a test of accuracy showed a $4.8 \%$ error rate in measuring total distance covered and a test of intra-tester reliability reported a technical error of measurement (TEM) of 5.5\%. ${ }^{[2]}$ These 
1 TEM values can therefore be taken into consideration when interpreting the raw data. Recent

2 technological developments have also led to increased miniaturisation and increased

3 portability. ${ }^{[47]}$ An alternative device known as the Biotrainer is also being produced by Citech

4 Holdings Pty Ltd. ${ }^{[48]}$ This system is described as a disposable patch, similar to a band-aid,

5 worn by the athlete which provides GPS tracking data both indoor and outdoor as well as reportedly supplying real-time biofeedback on nine physiological outputs such as heart rate,

7 body temperature and hydration level. Nevertheless, GPS receivers are still subject to

8 problems of accuracy as the magnitude of error depends on land configuration and the number

9 of available satellite connections. Furthermore, in previous systems, data were usually

10 collected at one measurement per second which was insufficient in frequency for measuring

11 detailed variations in speed and direction. However, the latest GPS receivers ${ }^{[45]}$ are now reportedly capable of logging data at frequencies of 50 measurements per second. Although this development has potential to provide much more precise data and could be very useful in speed and agility assessments, the volume is therefore 50 times larger and creates potential problems in unit size, storage capacity and battery life. This new facility may also require extra manual work in data interpretation which could ultimately delay any feedback. It therefore becomes the challenge for developers and researchers to investigate the optimal measurement frequency to provide appropriate data. Although, the price of individual GPS units means they are now more within the reach of the non-elite player, purchasing enough receivers to cover the needs of every member of a squad of players may still be beyond all but the wealthiest of clubs.

\section{Main issues in contemporary motion analysis technologies}

242.1 Validity, Objectivity and Reliability 
The methodologies employed to collect motion-analysis data must meet the

2 requirements for scientific criteria for quality control. ${ }^{[8]}$ These specifications include 3 reliability, objectivity and validity. There is a need for a detailed analysis of the errors 4 associated with the analytical procedures used by the systems. ${ }^{[27]}$ To date, many of the 5 contemporary commercial motion-analysis systems already discussed in the present review have not undergone satisfactorily quality control checks. Other than manufacturers'

7 statements, very little scientific evidence exists to verify validity claims. ${ }^{[24]}$ The lack of a 8 single validation test protocol considered the 'gold standard' for testing the validity, reliability 9 and objectivity of motion analysis data collection methodologies, may be one reason for this low number of validation studies. Any validation protocol itself must also have undergone 11 quality control testing and be easily transferable across the range of systems currently used in elite soccer. However, there are various issues that can play a part in preventing researchers from designing and undertaking validation projects. For example, researchers may face 14 logistical problems such as gaining access to test systems using the playing facilities within soccer stadia. The current laws of the game also prohibit players from wearing electronic equipment for measuring the reliability of movement measurements within competition conditions.

If human input for data collection is still required when using a contemporary system, inter-observer and intra-observer reliability testing of the same competitive match(es) must be undertaken to assess measurement error. When automatic data collection processes such as tracking movement on video or via a GPS are employed, it is important to test the intrareliability of the system itself by analysing the same match several times. It is also necessary to check the reliability of data by examining within-subject (player) error across a number of 24 games, which has rarely been achieved in the literature. ${ }^{[27]}$ Similarly, to ensure full validation of a system, comparison of the measurements obtained using contemporary analysis software 
1 and equipment should be made with those obtained from already established methods. There

2 are also statistical considerations to be taken into account when examining the reliability of a

3 system. The statistical procedures used to compare reliability measurements and the amount

4 of disagreement between measurements deemed to be acceptable must be suitably defined at

5 the outset of the study. In addition, the statistical test selected should aim to show agreement

6 between observer measurements rather than differences. For more detailed information on

7 reliability checks in match analysis, see review by Drust et al. ${ }^{[27]}$

A validation procedure of a commercial match analysis system was designed by Di

9 Salvo et al. ${ }^{[35]}$ to compare data on running speeds of soccer players obtained via video-based

10 tracking against those obtained from timing gates measurements. The subjects were asked to

11 perform a series of short runs at different determined speeds over several marked courses.

Correlation coefficients and absolute reliability coefficients between velocity measurements over runs of 50 and 60 metres obtained from both systems were high (r=0.999; total error 0.05 , limits of agreement 0.12 ) indicating that the system can be confidently used to provide an accurate recording of running speed during soccer play. However, as this type of semiautomatic tracking system requires manual input, it would have been beneficial to have compared the reliability of data obtained from the runs by distinguishing between human and automatic tracking of the subjects' movement. Similarly, an intra- and inter-observer reliability study comparing the data from the whole duration of several matches played under real competitive conditions is necessary to gain an idea of the overall reliability of the system output. Validation protocols of video-based tracking systems which use marked courses or zones to evaluate running speed and distance, should ensure the inclusion of all the different types of running actions previously identified by means of motion analyses. For example, as well as running in a straight line, moving in backwards and sideways directions, turning, shuffling and jumping actions and dribbling should be carried out by test subjects. Similarly, 
1 adding and removing players to the area analysed are advisable to ensure analysis conditions

2 are close to those observed in real competition. Validation procedures should also be carried

3 out under different climatic conditions (such as variations in light) as environmental variables

4 can affect the quality of the video recordings used for computer tracking. ${ }^{[8]}$

It is important to assess the reliability of data for each individual class of movement

6 intensity. In a previous study, data obtained from manual coding using a computer interface of the time spent in high-intensity running by English Premier League players (during the same match) were compared between two different observers. ${ }^{[49]}$ There was a relatively low level of 9 inter-observer reliability between measurements and a significant systematic bias between observers for the percentage time spent performing high- intensity activity (t59 $=2.7, \mathrm{P}<$ 0.01) with one observer recording much higher values than the other observer. The validation of a motion-analysis system employing photogrammetric techniques to obtain the $\mathrm{x}$ - and $\mathrm{y}$ positional coordinates from digital video images of soccer games has recently been achieved. ${ }^{[50]}$ The test subjects were instructed to run at paced speeds over follow preestablished trajectories with defined distances and the measurements were subsequently compared to the distances obtained by means of the photogrammetric method. Results showed an error in distance measurement of less than $1.5 \%$ for each of the movement categories. In the same study, the accuracy of the system to determine general position and distance of targets was also determined. For this process, 40 markers were randomly distributed over a football pitch and the pitch was filmed from the main stand. The position of these markers was determined using a pre-calibrated 50-m measuring tape and later obtained through digitization of the frames. A low root mean square error for reconstruction of the coordinates in the $\mathrm{x}$ - and $\mathrm{y}$-axis was obtained ( 0.23 and $0.17 \mathrm{~m}$ respectively). Similarly, the authors reported an error of less than $2 \%$ for reconstructing the distance between two 25 individual coordinates. Whilst the accuracy of this system in determining distances covered 
1 by players over set running courses seems sufficient, it would also have been pertinent to 2 compare results from whole competitive games against hand-based motion-analysis 3 methods $^{[11,20]}$ which have previously demonstrated high levels of reliability and validity 4 (coefficients $>0.9$ ). This validation requirement should apply even if the measurement error in 5 novel experimental technology may be less than that for a reference method such as that used 6 by Reilly and Thomas ${ }^{[11]}$.

In a recent comparison of global positioning and manual computer-based tracking systems for measuring player movement distance during Australian Rules Football games, ${ }^{[24]} \mathrm{a}$ range of ways was used to determine the validity and reliability of these methods for measuring distance covered. Validity checks for both systems were undertaken by comparing

11 the data obtained by each system for distance covered by players running over a predetermined marked circuit against the distance calculated by a calibrated trundle-wheel pedometer. Intra-tester reliability of the distance calculated by both systems was also assessed over a range of running courses. Inter-tester reliability of distance covered from the tracking system was assessed by comparing data obtained in both competition and over a marked course. A comparison of the two tracking technologies for measuring movement distances was performed when data were collected simultaneously. Players wearing a GPS receiver ran around circuits of different lengths and geographic layout whilst two observers simultaneously tracked their movements. A calibrated trundle-wheel pedometer was then used to verify the actual track distance following the completion of the circuit. Both the GPS and the tracking system were found to overestimate the true distances (on average less than 7\%) travelled by players. The authors considered that these relatively small overestimations combined with an acceptable level of relative technical error of measurement both within and

24 between trackers should not prevent the use of either of these technologies to monitor player movements. However, this particular manual tracking system relies on the subjective skills of 
1 observation and visual judgement on the part of the tracker. An omission was therefore the

2 lack of testing of the reliability of data for the individual classes of movement and notably for

3 movements at high-intensities which tend to be overestimated. ${ }^{[49]}$

\subsection{Interpretation of Results}

Ultimately, contemporary measurement systems are based upon gathering data concerning the events in a match and the physical efforts of the players. In terms of the latter, the workload of the players is based around data collected on speed, distance and time and complied to form an assessment of physical exertion. However, the distance covered by players has been an area which has been adversely affected by methodological differences. This includes a lack of standardised approaches and a need for a more rigorous analysis of data. Furthermore, it is important to recognise that physiological evaluation is limited due to the fact that the method makes the general assumption that energy is expended only when the player travels to a new location on the pitch, with sprinting usually classified as the most exertive motion. This is an important issue as this provides an underestimation of total energy expenditure of the players as several high intensity movements are performed in soccer match-play without obvious changes of location on the pitch, for example a vertical jump, competing for possession or a high-speed shuffle. Furthermore, many contemporary systems assume players only travel in a forward direction and therefore do not provide detailed information on backward, sideways or other unorthodox movements which have been reported as more physiologically demanding than movements performed forwards at the same velocity. ${ }^{[8,9]}$ To this end, other parameters such as agility (acceleration, deceleration, changing direction), physical contact, and 'on-the-ball' activity also contribute to physiological energy expenditure, and critically, the sequence in which these activities happen. Considering the dynamic nature of movements in soccer, this lack of information restricts a truly valid and 
1 thorough assessment of a player's expenditure in match-play. However, if the file containing

2 the raw positional data can be accessed as in the case of contemporary GPS receivers for team

3 sports $^{[45]}$, then algorithmic filtering may be employed to obtain these missing data.

Some major limitations exist with systems that centre on measuring distance covered through measurement of time spent in motion at different speeds. To this end, there is an inconsistency in the agreement of what speed thresholds to be used in soccer with, for example, values for sprints set at speeds of $>30 \mathrm{~km} / \mathrm{h}^{[15]},>23 \mathrm{~km} / \mathrm{h}^{[35]}$ and $>24 \mathrm{~km} / \mathrm{h}^{[51]}$ having been reported. These discrepancies in the definition of speed thresholds make it difficult to compare work-rate data between different studies. However, the very latest software used to analyse work-rate data allows end-users to define their own speed thresholds permitting a more objective means of analysing and comparing the physical efforts of players according to different intensities of movement. ${ }^{[34]}$

One of the main concerns with motion analysis data is the stringency of the speed thresholds used to categorise the motion types. Essentially, results are created by objective measurement systems by acknowledging the frequency of the occasions that a player enters a certain threshold and then the time that player spends within that threshold and subsequently calculating distance covered. However, if a player were to perform a single effort at speeds on the boundary of a particular threshold, it is quite possible that the data reveals that multiple efforts have been performed if the boundaries have been crossed. For example, if a threshold for 'sprinting speed' was set at efforts $>24 \mathrm{~km} / \mathrm{h}$ and a $1 \mathrm{~Hz}$ (second-by-second) raw output over 7-s reads 22-23-24-26-23-25-23, it is interpreted that this player sprinted on two occasions when realistically (subjectively) it could and perhaps should be only interpreted as once. Furthermore, it should also be noted that the interpretation here is that the player 'sprinted' for a certain duration, although this only accounts for the time spent $>24 \mathrm{~km} / \mathrm{h}$. This 
1 for the acceleration phase of this 'sprint'. Instead, the interpretation should be that the player

2 achieved speeds $>24 \mathrm{~km} / \mathrm{h}$ for a certain duration. This fact therefore applies to all motion

3 category thresholds used to evaluate performance as it will also affect total frequencies and

4 mean durations of each motion type. One way of combating this error is to filter or smooth the

5 data using mathematical algorithms to make inferences on the data. For example, this may

6 also be used to illustrate differences between rapid or gradual accelerations or decelerations

7 by determining how quickly a player has moved through different threshold zones. However,

8 this use of multiple equations within a data set requires further validation of the system.

Similarly, although differences have been identified in total distance covered in various levels of performance, with higher levels of performance corresponding with higher 11 distances ${ }^{[15]}$, caution must also be taken when assessing a player's match performance based on the total distance covered. In this respect, players may be inefficient with their movement and in essence 'waste energy' by performing unnecessary movements which may actually be detrimental to the team tactic but result in a large distance covered which may therefore be open to misinterpretation. Alternatively, a player may remain in low-intensity motion for a significant percentage of a match through being highly efficient in the movement selection. This would produce a below average total distance covered, number of sprints, workload and work-rate yet this player may have had the highest impact on the team's performance. In turn, an opposing player who is responsible for marking this type of player may also appear to have done less workload than normal.

Finally, the overall reporting of results is usually provided macroscopically and in isolation. Traditionally, values for total overall distance, as well as total, frequency and mean distance, time and/or percentage time spent in each motion type are reported. ${ }^{[9]}$ This huge amount of data for each match can be a challenge in itself for professional soccer staff to make true assessments of match performance, monitor workloads and plan appropriate 
1 physical fitness regimes. In this respect, a recent programmed exercise protocol for netball

2 based on mean 'bursts' of high intensity activity and 'recoveries' of low to moderate intensity

3 based on time-motion analysis proved to be ineffective in enhancing match-play specific

4 physical fitness. ${ }^{[52]}$ To this end, a full range of 'bursts' and 'recoveries' are sought to design

5 physical conditioning programmes that are specific to soccer match-play. Consequently, ratio

6 scales should be used to present data based on levels of intensity. ${ }^{[53]}$

The holistic approach of reporting work-rate data ignores the interaction between and within motions, movements and playing activities. Therefore, it is also important to perform temporal pattern detection to identify patterns within the data. In this respect, the detection of patterns that are not identifiable through simple observation has great benefit not only in soccer match-play variables but also in establishing the specific physical performance demands. ${ }^{[54]}$ A temporal pattern (T-Pattern) is essentially a combination of events where the events occur in the same order with the consecutive time distances between consecutive pattern components remaining relatively invariant with respect to an expectation assuming, as a null hypothesis, that each component is independently and randomly distributed over time. The method of T-patterning has already been employed to establish playing patterns in soccer by identifying complex intra- and inter-individual patterns for both individuals and teams using the detected behavioural patterns in combination with elementary statistics. ${ }^{[55]}$ Figure 1 displays a player's movement pattern which identifies a varied range of motions. This particular pattern begins with the player shuffling backwards and then sprinting forwards and slowing down in which he shuffles at high intensity. From this point he skips sideways left at low intensity, turns left and jogs forward at low intensity, gradually increasing pace into a run and changing direction by moving diagonally left to complete the complex pattern.

24 Preliminary investigation of pattern complexity between player positions suggests that a higher number of different patterns and pattern occurrences are detected for defenders than 
1 forwards and midfielders. ${ }^{[54]}$ The same also seems to apply for length of patterns. These

2 findings, and their significance, need further examination, although they could be very useful

3 for creating specific training programmes according to individual positional requirements.

\section{3. Contemporary motion analysis research}

$6 \quad 3.1$ Analysis of data on overall work-rate

There is a growing interest amongst practitioners within elite soccer in the work-rate characteristics of soccer players using the data obtained from the various techniques and technologies described in the previous section. Generally, the overall work-rate in field sports can be expressed as distance covered in a game, given that this measure determines the energy expenditure irrespective of the speed of movement and the individual contribution towards the total team effort. ${ }^{[9]}$ This activity can then be broken down into discrete actions for each player across the whole game for classification according to intensity, duration and frequency. Although caution should be made when comparing the results of various studies due to the differing methodologies employed to obtain data, contemporary outfield male elite soccer players cover on average 9-12 km per match, ${ }^{[15,25,56,57]}$ whilst some players may attain distances

17 of around $14 \mathrm{~km}$ (see Table II). ${ }^{[35,58]}$ Observers of elite female soccer players have generally reported lower results than elite male players in terms of overall distance covered $(8.7-12 \mathrm{~km})$

19 but a similar level of physiological strain. ${ }^{[16,19,59-61]}$

From a coaching perspective, it may be of value to compare the overall distance run by

21 individual players with that of team mates or opposition players to ascertain relative exertion rates. However, this distance may not be a fair reflection of a player's performance as playing style, team formation, technical actions and tactical role also influence overall work-rate. For example, Rienzi et al. ${ }^{[62]}$ presented evidence that the distance covered by South American players was about $1 \mathrm{~km}$ less than the output of professionals in the English Premier League. 
1 The authors suggested that the higher sustained pace by players in the English game could

2 explain this disparity. However, no motion analysis study has yet been conducted to compare

3 the distances run by elite soccer players belonging to teams across a larger range of national

4 championships.

Measuring the total distance run may also help in examining the evolution of workrates over several seasons to determine if the physical requirements of the game are the same and if current training programmes and fitness tests are still optimal. Professionals in the English Premiership tend to cover greater distances during matches than those in the former $1^{\text {st }}$ Division (pre-1992) which has had obvious consequences on contemporary fitness training programmes. ${ }^{[13]}$ Data presenting the total distance run by 300 professional European midfield players have recently confirmed this upward trend. ${ }^{[34]}$ Although contemporary elite players are running greater distances than in previous years, the effects of playing position on distance run is consistent across the last three decades. ${ }^{[9]}$

A pertinent coaching issue may be to look at a division of the total distance run into data for defending (opposition in possession) and attacking (own team in possession) play. This comparison may help determine whether players are working as much in a defensive role as they are in attack. At present, this factor has not been examined in the scientific literature although results are likely to be affected by the tactical role of players. For example, a 'holding' midfielder deployed on mainly defensive duties will no doubt cover less distances compared to other midfielders when his/her team is attacking. Another concern may be to identify if physical demands are comparable between different levels within elite soccer, for example between the various divisions in professional leagues. A comparison of professional Italian and elite Danish players showed that the former covered a significantly higher distance during games. ${ }^{[15]} \mathrm{A}$ motion analysis study of the total distance run by the same elite females competing at both national (for their clubs) and at international level (for their national team) 
1 established that these players ran significantly greater distances when competing at

2 international level. ${ }^{[19]}$ The observation highlights the need to take the level of competition, and

3 perhaps the importance of the game, into consideration when interpreting data on motion

4 analysis of match-play.

It is not feasible to use the total distance run to compare the overall physical

6 contributions of players when there is a difference in the overall duration of games. For example, different categories of age in youth soccer generally play games of different time length and other types of soccer such as futsal are limited to a total of 40 minutes play. An

9 alternative means of comparing the overall physical contributions of players is to calculate a relative measurement of performance by correcting the absolute value (total distance covered)

11 for the match, to a minute by minute analysis of distance run. Recent studies have shown that 12 the intensity of play in professional futsal ${ }^{[63]}$ was higher compared to elite players competing 13 in the Australian National league ${ }^{[30]}$. The futsal players covered on average 117 meters per 14 minute compared to 111 meters per minute for the Australian players indicating that the intensity of the game of futsal is higher than that for traditional soccer games.

\subsection{Categories of movements}

In field sports such as soccer, movement activities are generally coded according to their intensity which is determined by the speed of actions. When evaluating performance, the frequency of each type of movement and the time spent or distance run in each movement can be analysed. The main categories generally used to analyse soccer work-rate are classed as standing, walking, jogging, cruising (striding) and sprinting. These categories have recently been extended to include other activities such as skipping and shuffling. ${ }^{[26]}$ Most activities in

24 soccer are carried out at a sub-maximal level of exertion, however, there are many other game-related activities which must be taken into account such as alterations in pace, changes 
1 in direction, execution of specific game skills and tracking opponents which will be examined

2 later in this review. Elite players spend the majority of the total game time in the low-intensity

3 motions of walking, jogging and standing. ${ }^{[13,15,34]}$ In comparison, high-intensity efforts

4 (cruising and sprinting) constitute around $10 \%$ of the total distance covered. ${ }^{[3,9]}$ This finding

5 compares to analysis of performance in professional futsal games where the percentage of the total distance covered spent in high intensity is almost a quarter (22.6\%) and can, on

7 occasions, exceed a third. ${ }^{[63]}$ Research on females has shown that these players spend more 8 time in lower intensity activities compared to males which may be explained by biological 9 differences such as endurance capacity. ${ }^{[64]}$

In soccer, activities at lower levels of intensity such as jogging and walking tend to dominate work-rate profiles. However, the impact of high-intensity efforts in match-play cannot be over-emphasised and it has been suggested that this feature may be the most appropriate means of evaluating and interpreting physical performance. ${ }^{[16,56]}$ Measurement of high-intensity exercise, for example, every 5 min during the course of the game, is an alternative way for coaches to evaluate overall work-rate. High-intensity exercise is a constant feature across matches ${ }^{[9]}$ and games are often won or lost on successful attempts at scoring carried out at high speed. ${ }^{[64]}$ The high-intensity category of work-rate includes the addition of cruising and sprinting actions which are pre-determined according to running speed. In elite soccer, players generally have to run at a high-intensity every $60 \mathrm{~s}$ and sprint all-out once every 4 min. ${ }^{[13]}$ However, Di Salvo and co-workers ${ }^{[34]}$ presented evidence that the number of sprints made per player ranges greatly (from 3-40). These authors suggested that this finding strongly depended upon individual playing position.

Because of the intermittent nature of the game, performance can be enhanced through improving players' ability to perform high-intensity work repeatedly. The timing of anaerobic efforts, their quality (distance, duration) and the capacity to repeat these efforts, whether in 
1 possession of the ball or without, are crucial since the success of their deployment plays a

2 critical role in the outcome of games. ${ }^{[8]}$ Players in successful teams competing within the same

3 elite league were reported to perform more high-speed running and sprinting in the most

4 intense periods of the game and more sprinting over the whole 90 minutes compared to less

5 successful teams. ${ }^{[65]}$

In elite soccer, the average distance and duration of sprints are short as evidence has shown that these activities are rarely more than 20 metres in length and tend to last around 4 seconds ${ }^{[3,34,57]}$. These findings imply that when a player is required to sprint, his or her acceleration capabilities may be of greater importance than their maximal running speed as the tactical demands of the game probably render it unnecessary to attain maximal speeds. Improving performance in these actions will help players in many aspects of their game, such as being first to the ball or getting away from a marker. For example, if a player tends to lose out by poor acceleration or lack of speed over a short distance, the trainer could suggest an individual speed development programme. A more detailed motion-analysis study on the characteristics of sprint patterns of players during competition could be beneficial. For example, no information is available on whether sprints commence from a variety of starting speeds such as a standing start or when jogging and, if so, does such differentiation also exist between playing positions. A recent study on elite rugby union players showed that forwards commenced these actions most frequently from a standing start (41\%), whereas backs sprinted from standing (29\%), walking (29\%), jogging (29\%), and occasionally striding

$21(13 \%)$ starts. ${ }^{[66]}$ Practitioners designing conditioning programmes would no doubt benefit from this information by ensuring that training sessions involve the actual movement patterns performed in matches. The programme can then provide sufficient overload through careful manipulations of the match demands in preparation for competition. This may involve 
1 alterations in playing time, size of pitch or number of players involved in order to increase the 2 training intensity.

In soccer, only a small percentage of the total distance covered by players is in

4 possession of the ball. Nevertheless, evidence from a field test of maximum oxygen

5 consumption has shown that running with the ball significantly raises oxygen consumption

6 and energy expenditure and should be taken into account when evaluating player efforts. ${ }^{[67]}$

7 The vast majority of actions are "off the ball", either in running to contest possession, support

8 team-mates, track opposing players, execute decoy runs, counter runs by marking a player, or

9 challenge an opponent. These actions often require frequent changes in movement activities

10 such as accelerations and decelerations, changes of direction, turns, unorthodox movement

11 patterns (backwards and sideways runs) and significantly contribute to additional energy

12 expenditure. ${ }^{[8]}$ The latest GPS systems are reported to enable the quantification of the stress

13 placed upon players from accelerations, decelerations, changes of direction and impacts,

14 permitting the individualisation and optimisation of exercise and recovery programmes ${ }^{[45]}$

15 although this claim has yet be scientifically validated. A challenge to future researchers is to

16 investigate and combine data on both contacts, collisions and tackles and on motion analysis

17 categories into a single index of training and competition loading.

Two studies have recently been undertaken to investigate deceleration ${ }^{[68]}$ and turning ${ }^{[69]}$

19 movements in professional soccer. Players were shown to perform an average of 54.1

20 deceleration movements and 558 turning movements, during 'purposeful movement' passages

21 from FA Premier League matches. The authors suggested that both these types of actions are

22 a common and highly important part of the modern game and there is a particular need for

23 developing specific deceleration and turning exercises in strength and conditioning training

24 sessions. An investigation into whether the inclusion of an enforced deceleration phase on repeated sprint efforts would cause greater fatigue and slower sprint times compared to efforts 
1 undertaken without this phase may be of interest in further understanding match performance

2 and optimising fitness training programmes.

The activity profile of players may be influenced by the style of play used by

4 individual clubs and by regional differences. Such regional differences in performance are 5 important as players moving between countries will probably need time to adapt both 6 physically as well as tactically to the particular style of the different leagues. Nevertheless, 7 there is still a lack of studies attempting to address either cultural or geographical differences 8 in the work-rate pattern ${ }^{[27]}$ especially at international level or between various professional 9 leagues. Similarly, motion-analysis research on the work-rate performance characteristics of 10 female and in particular younger players is still relatively limited in the literature. Results of a 11 recent study on elite youth Brazilian players belonging to under 15, under 17 and under 20 age groups indicated significant differences in both overall work-load and individual playing

13 positions according to player age. ${ }^{[70]}$ The age of players should therefore be a relevant factor 14 when evaluating work-rate profiles.

3.3 Determining positional demands

17
Understanding the work-load imposed on top-level soccer players according to their positional role during competitive matches is necessary to develop a sport specific training protocol. ${ }^{[34]}$ Contemporary data ${ }^{[13,15,34]}$ generally confirm the previously identified trend ${ }^{[11,20]}$ that midfield players generally cover greater distances per game than defenders or forwards. Goalkeepers usually cover much lower distances (around $4 \mathrm{~km}$ ) per match. However, individual differences in the distance covered are not just related to a division into basic traditional team positions of defenders, midfielders and attackers. For each playing position, there may be a significant variation in the physical demands depending on the tactical role and the physical capacity of the players. For example, Barros et al. ${ }^{[25]}$ and Di Salvo et al. ${ }^{[34]}$ 
1 showed that in professional Brazilian and European soccer, fullbacks ran significantly further

2 distances than central defenders. Similar results between defensive positions have also been

3 obtained for international female soccer players. ${ }^{[61]}$ These results highlight that individual

4 differences in playing style and physical performance should be taken into account when

5 planning training and nutritional strategies. ${ }^{[71]}$

Again, marked differences in the intensity of various running activities exist across the

7 various playing positions. A detailed analysis of English Premier League players showed that playing position (defender, midfielder and attacker) had a significant influence on the time spent sprinting, running, shuffling, skipping and standing still. ${ }^{[21]}$ Rienzi et al. ${ }^{[62]}$ observed that defenders perform more backward running than strikers. Similarly, it has been reported that Premier League midfielders and strikers engaged in significantly more of the 'other' type of movements (jumping, landing, diving, sliding, slowing down, falling and getting up) compared to the other positions. ${ }^{[21]}$

Analysis of work-rate categories also suggests that training and fitness testing should be tailored specifically to positional groups (e.g., separation between central and external midfielders) rather than simply differentiating between forwards, midfielders and defenders as each positional group has its own unique physical demands. For example, a variation in the distance covered at high intensity of $1.9 \mathrm{~km}$ among the midfield players in the same game has been reported. ${ }^{[15]}$ Variations in work-rate between players may imply that not all positions may be taxed to full capacity in every game. Findings from a study comparing 123 professional European players showed that central defenders sprinted significantly less distances than fullbacks. ${ }^{[34]}$ A large-scale study on professional Spanish soccer reported a significant difference in the total distance run in sprint by wide midfielders compared to central midfielders. ${ }^{[72]}$ This research again demonstrates the need for a criterion model in order to tailor training programmes and strategies to suit the particular needs of individual playing 
1 positions. Research dividing the high-intensity efforts of players for defending (opposition in

2 possession) and attacking (own team in possession) play would be pertinent to determine

3 whether positional role determines the physical contribution of players according to whether

4 their team is in possession or not.

Motion analysis and its application to training must also take into account the relationship between the physical and technical demands of games. For example, match data on professional English players show that forwards tend to receive the ball more frequently when cruising and sprinting than defenders and midfielders, indicating that the ability required to implement technical skills at pace when attacking is important for this position. ${ }^{[73]}$

3.4 Use of motion-analysis in studies of fatigue In motion-analyses of soccer, data may be split into distinct time frames to help establish if work-rate varies with time or task. According to analyses and performance measures during elite match-play, fatigue manifested as a decreased performance seems to occur at three different stages in a game: (1) after short-term intense periods in both halves; (2) in the initial phase of the second half; and (3) towards the end of the game. ${ }^{[56]}$ Simple comparisons of the overall work-rate between first and second halves of matches can indicate the occurrence of fatigue although it may be more closely identified if activities during the game are broken up into 15-min or 5-min segments. ${ }^{[8]}$ Minute by minute analysis of work-rate throughout a game has also been employed as a possible means of identifying a drop off in 21 physical performance. ${ }^{[25]}$

In soccer, the evidence of a difference in the total distance covered between halves is inconsistent and a significant decrement does not necessarily occur in all players especially if 24 players operate below their physical capacities in the first half. Therefore, a simple comparison of the overall distance run per half may not be a valid means to allow 
1 interpretation on whether or not a player has experienced fatigue. Nevertheless, Table III

2 presents data from various studies comparing the total distance run by elite soccer players for

3 the two halves of the game. An average difference of $-3.1 \%$ in the total distance run between

4 halves (range $-9.4 \%$ to $+0.8 \%$ ) can be observed across all studies on elite soccer. The largest

5 difference between the total distance run in the first half compared to the second half was

6 reported for players participating in the Australian National Football League. ${ }^{[30]}$ Professional

7 Brazilian players have also been reported to cover significantly more distance in the first

8 half, ${ }^{[25]}$ whereas more recent data showed no significant difference in work-rates between

9 halves for elite Spanish players and other European players participating in Spanish League

10 and UEFA Champions League games. ${ }^{[34]}$ In this latter study, the data may have been

11 confounded as no mention was made as to the inclusion of substitutes and the effect their

work-rates may have had on the results. Nevertheless, individual teams and players may pace

13 their efforts in order to finish the game strongly. A comparison of total distance run between

14 match halves of the winners (Barcelona) and losers (Arsenal) of the 2005-06 UEFA

15 Champions league final showed that the Spanish players covered more distance in the second

16 half compared to the first half (5121 m versus 5218). ${ }^{[74]}$ In contrast, players belonging to the

17 losing team who completed the whole match, covered slightly less ground in the second half

18 (5297 m versus $5252 \mathrm{~m}$ ) compared to the first half suggesting they may have been forced into

19 a fatigued state. In this study, the data may have been confounded as Arsenal was forced to

20 play with ten players for the majority of the game due to the exclusion of the goalkeeper.

A $14 \%$ slower overall speed in the second half of the game when compared with the

22 first half has been reported in elite Australian soccer players. ${ }^{[30]}$ This result was attributed to

23 fewer observations of the low-intensity movements $(9.0 \%$ less walking and $12.4 \%$ less

24 jogging) and more stationary periods. Engagement in game events such as kicking and

25 passing was also $11.2 \%$ less frequent in the second versus first half of games. Similarly, a 
1 recent study of work-rates in professional Italian players examined the effects of fatigue on

2 technical performance. ${ }^{[75]}$ A significant decline between the first and second half was found

3 for both physical performance and some technical scores (involvements with the ball, short

4 passes and successful short passes). Minute-by-minute analysis of total distances covered by

5 Brazilian players revealed significant differences after the fifth minute of the game with

6 highly significant differences after the eighth. ${ }^{[25]}$ The authors suggested that this more detailed

7 analysis may allow a better understanding of fatigue. However, these results should be treated

8 with caution as it is highly unlikely that players experience fatigue so soon during a match.

9 This reduction in performance is more likely to be linked to play settling down after the

10 frantic first few minutes of the game where engagement is at its most intense. Indeed, a study

11 by Rahmana et al. ${ }^{[76]}$ yielded evidence that the majority of critical game incidents and the

highest intensity of activities were observed in the first 15 minutes in comparison to any other

13 period of the game.

A significant reduction in the distance run in exercise of medium-intensity ${ }^{[34]}$ and highintensity ${ }^{[33,77]}$ between halves has been reported in players competing in elite European soccer games and tournaments. In elite Scandinavian soccer players, the amount of high-intensity running was lower (35-45\%) in the last $15 \mathrm{~min}$ than in the first $15 \mathrm{~min}$ of the game with more than $40 \%$ of the players having their lowest amount of intense exercise in the last 15 min. ${ }^{[15]}$ This trend was confirmed in a study of elite female players where a marked decrease in the amount of high-intensity running within each half was observed and 13 out of 14 players did 21 their least amount of high-intensity running in the last 15-min period of the first or second 22 half. $^{[16]}$ Similarly, GPS-based tracking of activity patterns in professional Futsal players has shown that during the last period of the game, the number of bouts of high-intensity exercise 24 significantly decreased. ${ }^{[78]}$ However, the total distance covered or the amount of sprinting may 25 be unaffected between playing halves in certain players ${ }^{[25]}$ and the distance covered in high- 
1 intensity activities may even increase between halves ${ }^{[79]}$ and in the last few minutes of the

2 game. ${ }^{[8]}$ Players carrying out fewer actions at low or moderate intensity may be 'sparing" their

3 efforts for the final few crucial actions as their energy levels become depleted. Some players

4 demonstrating no decrease in performance between halves or in the final quarter of the match

5 may have paced themselves in order to finish the game strongly. A pertinent study may be to examine whether the type of competitive match affects work-rate and any subsequent reduction in performance. For example, it would be relevant to determine whether players tend to work harder or demonstrate greater fatigue during Cup games compared to league games or when playing against teams from lower standards of play.

Another method of examining fatigue may be to concentrate on the maximal speed or duration of individual sprints to determine whether a player's sprint performance is declining (e.g. is the player less quick?) towards the end of the match. The maximal sprint speed of an international midfield soccer player averaged every 5 min throughout the match has been 14 reported to decrease significantly towards the end of the match. ${ }^{[79]}$ However, as the data were drawn from a case study of one player, it is difficult to draw conclusions about the relationship between maximal sprinting speed and fatigue. In addition, soccer players may not always reach maximal speed during sprinting actions due to the tactical demands of the particular situations restricting the length of these runs. Work-rate analysis to determine whether there is a decrease in the capacity to accelerate rather than in maximal sprint speed towards the end of a game may be a more pertinent means of evaluating the occurrence of 21 fatigue although no study has as yet examined this feature. Nevertheless, work-rate information indicating fatigue towards the end of the game could lead the coach to change tactics or even make a substitution to avoid the opposition exploiting this emerging physical weakness. Substituting players before the onset of fatigue towards the end of the game may restore the imbalances in work-rate. Substitute players have been shown to cover significantly 
more ground at high-intensity during the final $15 \mathrm{~min}$ than the other players already present

2 on the pitch. ${ }^{[15]}$ The very latest video-tracking systems allow coaches to analyse work-rate in

3 real-time and make objective evidence-based decisions when attempting to identify players

4 who may need replacing.

Evaluating fatigue during match-play may lead coaches to examine if the intensity of

6 the following sprint is affected by the intensity of the previous sprint (e.g. if the sprint is long and at maximal speed). It may also be useful to look at the relationship between successive sprints and whether the intensity of the subsequent activities is affected e.g. if moderate intensity exercise has more of a negative impact on ensuing sprint performance than efforts at

10 low intensity. Individual sprints often depend on the requirements of the game situation, and 11 particularly the recovery allowed by the unpredictable nature of play. After the 5-min period during which the amount of high-intensity running peaked, performance was reduced by $12 \%$

13 in the following 5 min compared with the game average in elite players. ${ }^{[15]}$ Further data on $4^{\text {th }}$ 14 Division Danish players have shown that performance of the third, fourth, and fifth sprints carried out after a period of intense exercise during the first half was reduced compared with 16 before the game. ${ }^{[80]}$ This finding together with the observation that sprint performance measured at the end of the first half was the same as before the match, provided direct evidence that fatigue occurs temporarily during a game.

Fatigue may be evident as a prolonged recovery during the game, for example, increased time spent in low-intensity activities. The reason for this decline in performance could be repeated pressure from the opposition on an individual player, eventually leading to an inability to respond to game demands. Rampinini et al ${ }^{[81]}$ recently observed that the workrate of a team of professional soccer players was significantly influenced by the activity 24 profile of opponents. Fatigue during match-play may be transient, the player recovering once there is respite from the opponents. In this instance, tactical support for the player targeted is 
1 vital so that the offence from the opponents is not relentless. However, the same study ${ }^{[81]}$

2 showed that the total distance covered and the amount of high-intensity running during

3 matches were higher against the 'better' opponent teams compared to 'lesser' opponent

4 teams. This finding suggests that players can increase or decrease their work-rate according to

5 both the demands of individual matches and to the quality of the opposition.

A study of the relationship between match scoreline and work-rate in soccer showed that players performed significantly less high-intensity activity when winning than when the score was level. ${ }^{[82]}$ Players also performed significantly less high-intensity activity when losing than when the score was level. The authors suggested that players on teams that are winning relax their work-rate, allowing opponents back into the game, and that players on teams that are trailing may lose the motivation to maintain a sufficient work-rate. When a team is ahead however, forward players perform significantly more exercise although this only appears to relate to the $\sim 10$ min period directly after a goal has been scored and the elevated work-rate is not ultimately sustained. ${ }^{[83]}$ This phenomenon merits further investigation, such as the impact of what match-time when goals are scored, actual score-line, significance of goal to score-line, as well as the impact of sendings off, specific formations and tactics on the work-rate of players.

Work-rates may vary between successive matches and different phases of the season with players periodically experiencing a possible decline in performance. Distance covered per match may vary which again suggests that players may not always be fully utilising their physical capacity. ${ }^{[8]}$ Reasons may include the specific tactical role chosen by the coach for the player or the self-imposed physical demands chosen by the player. Analysis of the total distance run by top-level players has been shown to vary significantly for individual players at 24 different stages of the season with players covering greater distances at the end of the 25 season. ${ }^{[15]}$ These discrepancies may be partly explained by changes in the physical condition 
1 of the players as the work-rate profile fluctuates in conjunction with the amount of training

2 that is completed by teams. ${ }^{[27]}$ During an intense schedule of three competitive matches in five

3 days in the English Premier League, total distance run did not vary significantly ${ }^{[84]}$ suggesting

4 this measurement may not be always be a valid indicator of a drop-off in performance during

5 the season.

Analysis of the physical efforts made in the various categories of movement may yield

7 information on whether the performance of a player is decreasing across different games. A

8 case report comparing the performance of an international French player over 5 successive

9 weekend matches showed little variation in the distance covered within the different

10 categories of running. ${ }^{[37]}$ In top-class Danish soccer, the coefficient of variation in high-

11 intensity running has been shown to be $9.2 \%$ between successive matches, whereas it was

$1224.8 \%$ between different stages of the season. ${ }^{[15]}$ The seasonal variation is most likely due to

13 alterations in fitness as the competitive schedule reaches a peak. However, few reports have

14 included the ambient conditions under which the games analysed were played. ${ }^{[27]}$ As soccer is

often played across all four seasons of the year, a future study to examine the relationship

between physical performance and playing conditions is recommended. Similarly, a study comparing work-rate performance between games played at varying times of the day would 18 be pertinent.

Teams may be required to play several games within a very short time frame and there is potential for residual fatigue and incomplete recovery to affect the movement patterns of 21 players during subsequent games. English Premiership soccer players were reported to 22 demonstrate a significant increase in recovery time between high-intensity efforts during an 23 intense period of three matches in five days. ${ }^{[84]}$ Further work is needed to identify if 24 performance is affected significantly between playing positions. Nevertheless, this finding 25 indicates that motion analysis data can play an important role in the approach to training and 
1 preparation before and during intense playing schedules. A future study could be designed to

2 look at a possible relationship between work-rate and injury occurrence. For example, a

3 decline in high-intensity performance over several consecutive matches may suggest

4 recuperation of a player is needed to avoid becoming susceptible to "overtraining". Similarly,

5 players returning after injury could have their profiles scrutinised to see how they have

6 recovered from intense periods of play or have their performance compared against a

7 benchmark profile obtained from previous matches.

Once a susceptibility to fatigue is identified in individual players, the possible reasons

9 for its occurrence should be explored. A fall in activity has been identified at the beginning of

10 the second compared to the first half. ${ }^{[56]}$ During the break, players tend to rest leading to a

11 drop in muscle temperature and subsequently to reduced performance levels. Mohr and co-

12 workers $^{[85]}$ presented evidence that undertaking a few minutes of low to moderate intensity

13 exercise during the pause may help players to 'ready' themselves and to perform better

14 physically straight after the break. As previously mentioned, fatigue can also occur as the end

15 of a game draws near. Reduced exercise performance at the end of soccer games may be

16 associated with lowered glycogen levels in individual muscle fibres. ${ }^{[71]}$ Therefore, adequate

17 attention to nutritional preparation (before, during and after matches) for competition is

18 necessary. The effectiveness of nutritional interventions could be monitored using motion-

19 analysis in match-play. Monitoring efforts during training by means of heart rate monitors

20 may also help coaches to avoid over-exerting players before matches and lowering their

21 energy stores. This information can now be combined with motion-analysis data from

22 electronic transmitters worn by players to determine individual physiological work-load

23 during training.

253.5 Other uses of motion analysis research 
Physiological studies and motion-analysis research on elite soccer players have

2 provided evidence that the total amount of work done during match-play is related to the maximal aerobic power of players which underlines the need for a high level of aerobic

4 fitness. ${ }^{[17,86]}$ This fact is especially important for certain playing positions such as midfield 5 players who are expected to work harder than the other outfield positions. Motion-analysis 6 studies may be employed to determine the effects of a training intervention on competition work-rate. Evidence shows that improvements in maximal oxygen uptake after an 8-week period of aerobic interval training corresponded to significant increases in the total distance covered during a match in elite junior players. ${ }^{[87]}$ Players who are aerobically well trained can maintain their work-rates better towards the end of the game than those of poorer aerobic fitness. ${ }^{[9]}$ Increasing maximal aerobic power may also aid recovery following successive bouts of high-intensity anaerobic efforts which produce transient fatigue. ${ }^{[37]}$ Its role is paramount as the recovery during repeated-sprint bouts in soccer is often of an active nature. A six-week programme of aerobic interval training undertaken by a group of amateur senior players led to an $18 \%$ increase in high intensity activities during competition. ${ }^{[17]}$

However, there is still a limited amount of knowledge on the effects of training programmes on actual performance of players in matches at elite level. In addition, no motion analysis study in elite soccer has as yet assessed the degree to whether the physical demands of the game are adequately replicated in training. For example, it may be worthwhile determining whether players undertake comparable amounts of high-intensity exercise (e.g., number and duration of sprints) in training as in match-play.

Over recent years, researchers have attempted to examine the validity of selected field tests by establishing links with on-field physical performance. The results from such tests can help determine the physical capacity of players and whether or not they may be susceptible to experiencing fatigue during match-play. The results from a 'repeated sprint ability' test have 
1 been highly correlated to the total distance covered in competition when sprinting. ${ }^{[36]}$

2 Similarly, a strong correlation has been observed between an intermittent recovery test and

3 both total distance run and sprint performance in elite females. ${ }^{[16]}$ Mohr et al. ${ }^{[15]}$ assessed the

4 relationship between physical fitness and match performance at two standards of soccer. They

5 compared the performance of top class soccer players to moderate level players both in an

6 intermittent recovery test and in work-rates in match play. The top players reported a superior

7 performance in the intermittent test and carried out significantly more high-intensity running

8 and sprinting during match-play.

These results justify the use of field and laboratory fitness testing of players and

10 linking the fitness data to work-rate assessments. However, the majority of research has been

11 carried on top-level Scandinavian players and further research (and on a larger scale) is needed to test these relationships in higher-level professional leagues and for differing age

13 groups. Furthermore, although various tests have been related closely with the physiological

14 load imposed through match-play, they still appear to lack ecological validity with respect to the motion types, directions, turns and intensities corresponding to the physical demands of the game and do not provide sufficiently adapted protocols for the individual playing 17 positions within soccer. ${ }^{[21]}$ These questions may be resolved using motion-analysis methods for determining precise locomotor activities during matches.

Motion analysis data drawn from match-play have also been employed to help design laboratory based protocols to simulate soccer specific intermittent exercise and examine

21 factors such as the effects of training interventions (Sari-Sarraf et al., 2006), ${ }^{[88]}$ nutritional strategies (Clarke et al., 2005), ${ }^{[89]}$ temperature (Drust et al., 2000) ${ }^{[90]}$ and fatigue on 23 performance. In the application to fatigue, an intermittent-exercise protocol was designed to 24 simulate the exercise intensities associated with playing a match in order to monitor the 
1 minutes. ${ }^{[91]}$ Results showed a progressive increase in muscle fatigue due to a decline in muscle

2 strength as exercise continued. Findings therefore had implications for competitive

3 performance and further understanding of the reported increased risk of injury towards the

4 end of the game. A future focus on the relationship between injury occurrence and fatigue

5 during actual competitive match play should be beneficial. For example, motion analysis

6 techniques could be employed to examine whether players are more at risk of injury after $7 \quad$ intense periods of high-intensity exercise.

\section{Overview}

A thorough understanding of the physical demands of soccer via information on player work-rates is required so that optimal training and preparation strategies can be constructed. As shown in the present review, an ever-increasing number of scientific investigations based on motion analysis techniques are providing important information on elite soccer play. These investigations have identified the activity profiles and physical requirements of contemporary elite soccer as well as the demands of individual playing positions. Motion-analysis research has also allowed investigators to determine the extent of fatigue experienced by players during competition as well as variations in physical performance over the course of the season. There are also possibilities to link fitness data to work-rate assessments and to determine the effects of training interventions on match performance.

Many of these investigations into work-rate have been possible due to major advances in computer and video technology which are providing more efficient ways of obtaining and analysing data especially on a larger scale. A plethora of commercial analysis systems is now available albeit with a price range varying by many thousands of dollars. The cost of many systems currently used in elite soccer is often prohibitive to all but the wealthiest clubs. 
1 Similarly, many researchers are still using older techniques, given that they do not have

2 access to these more advanced technologies due to the large costs associated with using them. Using information derived from these latest techniques, academics could start to test

4 and build upon existing research by exploring some of the gaps and questions identified

5 throughout this review. Furthermore, conducting research into how these technologies are

6 actually being put into use within coaching contexts would be pertinent as there is little 7 appreciation about how effectively and efficiently they are being translated and adopted by practitioners to prepare and develop members of their squad. This reservation applies both to the operator's comprehension and coaches' use of data derived from these tools. Additionally, the measurement precision and reliability of systems proven on the basis of sound scientific evidence have not always been satisfactorily demonstrated. No current method has been accepted as the 'gold' standard approach to work-rate analysis and few investigators have attempted to make comparisons between different methodologies and technologies. It is imperative that researchers investigate the scientific legitimacy of these systems so that applied practitioners and the academic community can be assured of their accuracy when employing these methods. Nevertheless, the perfecting of motion analysis technologies will no doubt continue as it has done over recent years with real-time analysis and application becoming the norm.

\section{Acknowledgements}

The authors have received no funding for the preparation of this article. The authors have no conflicts of interest that are directly relevant to the content of this review except that Christopher Carling and Lee Nelsen have previously participated to the development of the AMISCO Pro match analysis system and Jonathan Bloomfield was previously employed by Prozone Group Limited.

References 
1 1. Williams AM, Hodges NJ. Practice, instruction and skill acquisition in soccer: challenging 2 tradition. J Sports Sci 2005 Jun; 23 (6): 637-50

3 2. Reilly T, Williams AM, editors. Science and Soccer. London: Routledge, 2003

4 3. Stølen T, Chamari K, Castagna C. et al. Physiology of soccer: an update. Sports Med 2005; 35 (6): 501-36

4. Impellizzeri FM, Rampinini E, Marcora SM. Physiological assessment of aerobic training in soccer. J Sports Sci 2005 Jun; 23 (6): 583-92

5. Gilbourne D, Richardson D. A practitioner-focused approach to the provision of psychological support in soccer: adopting action research themes and processes. J Sports Sci 2005 Jun; 23 (6): 651-8

6. Lees A. and Nolan L. The biomechanics of soccer: a review. J Sports Sci 1998 Apr; (3) 16: $211-34$

7. Reilly T, Gilbourne D. Science and football: a review of applied research in the football codes. J Sports Sci 2003 Sep; 21 (9): 693-705

8. Carling C, Williams AM, Reilly T. The Handbook of Soccer Match Analysis. London: Routledge, 2005

9. Reilly T. Science of training: Soccer. London: Routledge, 2007

10. Reilly T. An ergonomics model of the soccer training process. J Sports Sci 2005 Jun; 23 (6): $561-72$

11. Reilly T, Thomas V. A motion analysis of work-rate in different positional roles in different positional roles in professional football match-play. J Hum Mov Stud 1976; 2; 87-97

12. James N. The role of notational analysis in soccer coaching. Int J Sport Sci \& Coaching 2006; 1 (2): 185-198 
1 13. Strudwick T, Reilly T. Work-rate Profiles of Elite Premier League Football Players.

$2 \quad$ Insight FA Coaches Assoc J 2001; 4 (2) 55-59

3 14. Reilly T, Drust B, Clarke N. Muscle fatigue during soccer match-play. Sports Med. In $4 \quad$ press

15. Mohr M, Krustrup P, Bangsbo J. Match performance of high-standard soccer players with special reference to development of fatigue. J Sports Sci 2003 Jul; 21 (7): 519-28.

16. Krustrup P, Mohr M, Ellingsgaard H, et al. Physical demands during an elite female soccer game: importance of training status. Med Sci Sports Exerc 2005 Jul; 37 (7): 1242-8

17. Impellizzeri FM, Marcora SM, Castagna C, et al. Physiological and performance effects of generic versus specific aerobic training in soccer players. Int J Sports Med 2006 Jun; 27 (6): 483-92

18. Randers MB, Jensen JM, Krustrup P. Comparison of activity profile during matches in Danish and Swedish premier league and matches in Nordic royal league tournament. J Sports Sci Med 2007; 6 Suppl. 10: 16

19. Andersson H, Krustrup P, Mohr M. Differences in movement pattern, heart rate and fatigue development in international versus national league matches of Swedish \& Danish

20. Bangsbo J, Norregaard J, Thorsoe F. Activity profile of competition soccer. Can J Sports Sci 1991; 16 (2): 110-116

21. Bloomfield J, Polman RCJ, O’Donoghue PG. Physical demands of different positions in

22. http://www.noldus.com (accessed, 25/0707)

23. Bloomfield J, Polman RCJ, O’Donoghue PG. Reliability of the Bloomfield Movement Classification. Int J Perf Anal Sport 2007 Jan; 7 (1): 20-27 
1 24. Edgecomb SJ, Norton KI. Comparison of global positioning and computer-based tracking systems for measuring player movement distance during Australian Football. J Sci Med Sport 2006 May; 9 (1-2): 25-32

25. Barros RML, Misuta MS, Menezes RP, et al. Analysis of the distances covered by first division Brazilian soccer players obtained with an automatic tracking method. J Sports Sci Med 2007; 6 (2): 233-242

26. Bloomfield J, Polman RCJ, O’Donoghue PG. The 'Bloomfield Movement Classification': Motion Analysis of Individual Players in Dynamic Movement Sports. Int J Perf Anal Sport 2004 Dec; 4 (2): 20-31

27. Drust B, Atkinson G, Reilly T. Future Perspectives in the Evaluation of the Physiological Demands of Soccer. Sports Med 2007; 37 (9): 783-805

28. Ohashi J, Togari H, Isokawa, M, et al. Measuring Movement Speeds and Distances covered During Soccer Match-Play. In Reilly, T., editor. Science and Football; London: E. \& F.N. Spon, 1988: 329-333

29. Miyagi O, Ohashi J, Kitagawa K. Motion characteristics of an elite soccer player during a game. Communications to the Fourth World Congress of Science and Football. J Sports Sci 1999; 17 (10): 816

30. Burgess DJ, Naughton G, Norton KI. Profile of movement demands of national football players in Australia. J Sci Med Sport 2006 Aug; 9 (4): 334-341

31. Ohta T, Togari H, Komiya Y. Game analysis of soccer. Tokyo: Japanese Football Association, 1969

32. Liebermann DG, Katz L, Hughes MD, et al. Advances in the application of information technology to sport performance. J Sports Sci 2002 Oct; 20 (10): 755-769

33. Brulé P, Carling C, David A, et al. AMISCO: The development of a computerised match analysis system to automatically track the movements of soccer players. Proceedings of 
the IV World Congress of Notational Analysis of Sport, Porto, University of Porto,

2 Portugal. 1998, 36

3 34. Di Salvo V, Baron R, Tschan H, et al. Performance characteristics according to playing position in elite soccer. Int J Sports Med 2007 Mar; 28 (3): 222-227

35. Di Salvo V, Collins A, McNeill B, et al. Validation of Prozone: A new video-based performance analysis system. Int J Perf Anal Sport 2006 Jun; 6 (1): 108-119

36. Rampinini E, Bishop D, Marcora, SM, et al. Validity of simple field tests as indicators of match-related physical performance in top-level professional soccer players. Int J Sports Med 2007 Mar; 28 (3); 228-35

37. Carling C. Getting the most out of football video \& match analysis. Insight FA Coaches Assoc J 2001; 5 (3): 16-17

38. Shiokawa M. Takahashi K, Kan A, et al. Computer analysis of a soccer game by the DLT

39. Fernandes, O Caixinha P. A new method of time-motion analysis for soccer training and competition. V World Congress of Science and Football, Lisbon-Portugal. Book of

41. http://www.datatrax.tv/ (accessed 28/07/07)

42. http://www.tracab.com/ (accessed 28/07/07)

43. http://www.inmotio.eu (accessed 02/08/07)

44. Larsson P. Global positioning system and sport-specific testing. Sports Med 2003; 33 
45. http://www.gpsports.com/ (accessed 02/08/07)

46. http://www.realtrackfutbol.com/ingles/start-gb.html (accessed 02/08/07)

47. Witte TH, Wilson AM. Accuracy of WAAS-enabled GPS for the determination of position and speed over ground. J Biomech 2005 Aug; 38 (8): 1717-22

48. http://www.citechholdings.com/index.html (accessed 08/08/07)

49. O’Donoghue P. Sources of variability in time-motion data; measurement error and within player variability in work-rate. Int J Perf Anal Sport 2004 Dec; 4 (2); $42-49$.

50. Mallo J, Navarro E, García-Aranda J, et al. Activity profile of top-class association football referees in relation to performance in selected physical tests. J Sports Sci 2007 May; 25 (7): 805-813

51. Roberts S, Trewartha, G, Stokes K. A comparison of time-motion analysis methods for field based sports. Int J Sports Phys Perf 2006; 1: 388-399

52. O'Donoghue, PG, Cassidy D. The effect of specific intermittent training on the fitness of international netball players. J Sports Sci (2002; 20(1): 56 - 57

53. O'Donoghue, PG. Analysis of the duration of periods of high-intensity activity and lowintensity recovery performed during English FA Premier League soccer. J Sports Sci 2003; 21(4): 285-286.

54. Bloomfield JG, Jonsson, K, Polman, RCJ, et al. (2005). Temporal pattern analysis and its applicability in soccer. In: (Edited by) L. Anolli, S. Duncan, M. Magnusson and G. Riva, The Hidden Structure of Social Interaction. From Genomics to Cultural Patterns. Amsterdam, IOS Press B.V., pp. 237-251

55. Borrie A, Jonsson GK, M.S. Magnusson. Temporal pattern analysis and its applicability in sport: An explanation and exemplar data. Journal of Sport Sciences, 2002; Oct, 20 (10), $845-852$ 
1 56. Mohr M, Krustrup P, Bangsbo J. Fatigue in soccer: a brief review. J Sports Sci 2005; Jun; 23 (6): 593-599

3 57. Thatcher R, Batterham AM. Development and validation of a sport-specific exercise protocol for elite youth soccer players. J Sports Med Phys Fitness 2004; 44 (1): 15-22

58. Fernandes $\mathrm{O}$, Caixinha $\mathrm{P}$, Malta $\mathrm{P}$. Techno-tactics and running distance analysis by camera. J Sports Sci Med 2007; 6 Suppl. 10: 204

59. Hewitt A, Withers R, Lyons K. Match analyses of Australian international women soccer players using an athlete tracking device. J Sports Sci Med 2007; 6 Suppl. 10: 107

60. Holmes L. A Physiological Analysis of Work-Rate in English Female Football Players. Insight FA Coaches Assoc J 2002; 5 (2): 55-59

61. Scott D, Drust B. Work-rate analysis of elite female soccer players during match-play. J Sports Sci Med 2007; 6 Suppl. 10: 107

62. Rienzi E, Drust B, Reilly T, et al. Investigation of anthropometric and work-rate profiles

64. Kirkendall DT. Issues in training the female player. Br J Sports Med 2007 Aug; 41 Suppl. 1: $64-67$

65. Randers MB, Rostgaard T, Krustrup P. Physical match performance and yo-yo IR2 test results of successful and unsuccessful football teams in the Danish premier league. $\mathbf{J}$ Sports Sci Med 2007; 6 Suppl. 10: 16

66. Duthie GM, Pyne DB, Marsh DJ, Hooper SL. Sprint patterns in rugby union players during competition. J Strength Cond Res. 2006; Feb; 20 (1): 208-14 
1 67. Rupf R, Thomas S, Wells G. Quantifying energy expenditure of dribbling a soccer ball in $2 \quad$ a field test. J Sports Sci Med 2007; 6 Suppl. 10: 132

68. Bloomfield J, Polman RCJ, O’Donoghue PG. Deceleration movements performed during FA Premier League soccer matches. J Sports Sci Med 2007; 6 Suppl. 10: 6

69. Bloomfield J, Polman RCJ, O’Donoghue PG. Turning movements performed during FA Premier League soccer matches, J Sports Sci Med 2007; 6 Suppl. 10: 9

70. Pereira Da Silva N, Kirkendall DT, Leite De Barros Neto T. Movement patterns in elite Brazilian youth soccer. J Sports Med Phys Fit 2007; 47 (3): 270-275

71. Bangsbo J, Mohr M, Krustrup P. Physical and metabolic demands of training and matchplay in the elite football player. J Sports Sci 2006 Jul; 24 (7): 665-674

72. Zubillaga A, Gorospel G, Mendo AH, et al. Analysis of high intensity activity in soccer highest level competition. J Sports Sci Med 2007; 6 Suppl. 10:

73. Williams A, Williams AM, Horn R. Physical and technical demands of different playing

74. Zubillaga A, Gorospe1 G, Mendo AH, et al. Match analysis of 2005-06 Champions

75. Rampinini E, Impellizzeri FM, Castagna C, Coutts AJ, Wisløff U. Technical performance

77. Di Salvo V, Baron R, Cardinale M. Time motion analysis of elite footballers in European

76. Rahnama N, Reilly $\mathrm{T}$, Lees A. Injury risk associated with playing actions during competitive soccer. Br J Sports Med 2002 Oct; 36 (5): 354-359 cup competitions. J Sports Sci Med 2007; 6 Suppl. 10: 14

78. Álvarez JCB, Castagna C. Activity patterns in professional futsal players using global position tracking system. J Sports Sci Med 2007; 6 Suppl. 10: 208 
1 79. Carling C. Football: A game of chance or does match analysis has the answers? Insight

$2 \quad$ FA Coaches Assoc 2002; 5 (3): 16-17

3 80. Krustrup P, Mohr M, Steensberg A, et al. Muscle and Blood Metabolites during a Soccer

4 Game: Implications for Sprint Performance. Med Sci Sports Exerc 2006; Jun; 38 (6): $1165-1174$

81. Rampinini E, Coutts AJ, Castagna C, et al. Variation in Top Level Soccer Match

82. O’Donoghue, PG, Tenga, A. The effect of score-line on work rate in elite soccer. J Sports Sci 2001; 19(2): $25-26$

83. Bloomfield, JR, Polman, RCJ, O’Donoghue, PG. Effects of score-line on work-rate in midfield and forward players in FA Premier League soccer. J Sports Sci 2004; 23(2): 191-

86. Reilly T. Motion analysis and physiological demands. In: Reilly, T. and Williams, A.M, editors. Science and Soccer. London: Routledge, 2003: 59-72

87. Helgerud J, Engen LC, Wisløff U, et al. Aerobic training improves soccer performance. Med Sci Sports Exerc 2001 Nov; 33 (11): 1925-1931

88. Sari-Sarraf, V., Reilly, T. And Doran, D.A. Salivary IgA responses to intermittent and continuous exercise. Int J Sports Med 2006; 27: 849-855 
1 89. Clarke, N.D., Drust, B., MacLaren, D.P.M. and Reilly, T. Strategies for hydration and

2 energy provision during soccer-specific exercise. Int J Sports Nutr Exerc Metab 2005; 15:

$3 \quad 625-640$

4 90. Drust, B., Cable, N.T. and Reilly, T. Investigation of the effects of pre-cooling on the 5 physiological responses to soccer-specific intermittent exercise. Eur J App Phys 2000; 81:

$6 \quad 11-17$

7 91. Rahnama, N., Reilly, T, Lees, A. and Graham-Smith, P. Muscle fatigue induced by 8 exercise simulating the work rate of competitive soccer, J Sports Sci 2003; 21: 933-942 


\begin{tabular}{|c|c|c|c|c|}
\hline Company/Institution & System & System type & Web Site & Study \\
\hline Cairos Technologies AG (Germany) & Cairos & Electonic transmitter & http://www.cairos.com & \\
\hline Citech Holdings Pty Ltd & Biotrainer & Electonic transmitter & http://www.citechholdings.com & \\
\hline Chukyo University (Japan) & Direct Linear Transformation & Automatic Video tracking & & Toki and Sakurai ${ }^{40}$ \\
\hline Inmotio Object Tracking BV & LPM Soccer 3D & Electonic transmitter & http://www.abatec-ag.com & \\
\hline Feedback Sport (Australia) & Feedback Football & Automatic Video tracking & http://www.feedbacksport.com/ & \\
\hline GPSports (Australia) & SPI Elite & GPS Tracking & http://www.gpsports.com/ & Edgecombe and Norton ${ }^{24}$ \\
\hline Hiroshima College of Sciences (Japan) & Direct Linear Transformation & Automatic Video tracking & & Shiokawa et al., ${ }^{38}$ \\
\hline National Defense Academy (Japan) & Triangular surveying & Triangular surveying & & Miyagi et al., ${ }^{29}$ \\
\hline Noldus & Observer Pro & Manual Video Coding & http://www.noldus.com & Bloomfield et al., ${ }^{21,23,26}$ \\
\hline Performance Group International (UK) & DatatraX & Automatic Video tracking & http://www.datatrax.tv & \\
\hline ProZone Holdings Ltd (UK) & ProZone & Automatic Video tracking & http://www.pzfootball.co.uk & Di Salvo et al., ${ }^{35}$ \\
\hline Real Track Football & Real Track Football & GPS Tracking & http://www.realtrackfutbol.com & \\
\hline Sport-Universal Process SA (France) & AMISCO Pro & Automatic Video tracking & http://www.sport-universal.com & \\
\hline Sportstec (Australia) & TrakPerformance & Computer Pen and Tablet & http://www.sportstecinternational.com & $\begin{array}{l}\text { Edgecombe and Norton }{ }^{24} \\
\text { Burgess et al., }{ }^{30}\end{array}$ \\
\hline Trakus Inc (USA) & Digital Sports Information & Electonic transmitters & http://www.trakus.com & \\
\hline University of Campinus (Brazil) & Dvideo & Automatic Video tracking & http://www.sport-universal.com & Barros et al., ${ }^{25}$ \\
\hline
\end{tabular}


1 Table II. Summary of data on the total distances run and according to playing position by

2 contemporary elite football players from 1999-2007 


\begin{tabular}{|c|c|c|c|c|c|c|c|c|}
\hline Reference & League/Competition level (sex) & Number & Total Distance $(\mathrm{m})$ & Fullback & Central defender & Midfielder & Forward & Method of measurement \\
\hline \multirow[t]{2}{*}{ Anderssen et al. ${ }^{19}$} & International Swedish/Danish (F) & 11 & 10000 & & & & & Manual video analysis \\
\hline & Elite Swedish/Danish (F) & 11 & 9700 & & & & & \\
\hline Barros et al., ${ }^{25}$ & Brazilian 1st Division (M) & 55 & 10012 & 10642 & 9029 & $10537^{*}$ & 9612 & Automatic tracking on video \\
\hline Brulé et al., ${ }^{33}$ & French Professional & 1 & 11000 & & & 11000 & & Automatic tracking on video \\
\hline Burgess et al., ${ }^{30}$ & Professional Australians (M) & 36 & 10100 & $8800 \#$ & & 10100 & 9900 & Manual computer pen \& tablet \\
\hline Di Salvo et al., ${ }^{34}$ & Profession European Leagues (M) & 300 & 11393 & 11410 & 10627 & $12009^{*}$ & 11254 & Automatic tracking on video \\
\hline Di Salvo et al., ${ }^{76}$ & Champions League matches (M) & 791 & 11010 & & 10020 & 11570 & & Automatic tracking on video \\
\hline Fernandes et al., ${ }^{39}$ & Portugese first division (M) & 3 & 12793 & 14199\# & & 12958 & 11224 & Automatic tracking on video \\
\hline Helgerud et al., ${ }^{87}$ & Elite Norwegian Juniors (M) & 9 & 10335 & & & & & Manual computer pen \& tablet \\
\hline Hewitt et al., ${ }^{59}$ & International Australian (F) & 6 & 9140 & 9010\# & & 9640 & 8510 & Global Positioning System \\
\hline Holmes ${ }^{60}$ & Elite English $(\mathrm{F})$ & 5 & 12400 & & & & & Manual video analysis \\
\hline Krustrup et al., ${ }^{16}$ & Elite Danish (F) & 14 & 10300 & & & & & Manual video analysis \\
\hline Impellizzeri et al., ${ }^{17}$ & Italian junior professionals (M) & 29 & 9890 & & & & & Manual video analysis \\
\hline Miyagi et al., ${ }^{29}$ & Japanese professionals (M) & 1 & 10460 & & & & & Triangulation/Camera potentiometer \\
\hline \multirow[t]{2}{*}{ Mohr et al., ${ }^{15}$} & Italian professionals $(\mathrm{M})$ & 18 & 10860 & $10980 \sim$ & $9740 \sim$ & $11000 \sim$ & $10480 \sim$ & Manual video analysis \\
\hline & Elite Danish (M) & 24 & 10330 & & & & & \\
\hline Odetoyinbo et al., ${ }^{83}$ & English professionals (M) & _- & 10659 & & & & & Automatic tracking on video \\
\hline Rampinini et al., ${ }^{36}$ & European professionals (M) & 18 & 10864 & & & & & Automatic tracking on video \\
\hline \multirow[t]{2}{*}{ Randers et al. ${ }^{65}$} & Danish Premier league (M) & 23 & 10800 & & & & & Manual video analysis \\
\hline & Swedish Premier League (M) & 23 & 10150 & & & & & Manual video analysis \\
\hline \multirow[t]{2}{*}{ Rienzi et al., ${ }^{62}$} & South American professionals (M) & 17 & 8638 & & & & & Manual video analysis \\
\hline & English professionals (M) & 6 & 10104 & & & & & Manual video analysis \\
\hline Scott and Drust ${ }^{61}$ & International English $(\mathrm{F})$ & 30 & 11979 & 12636 & 11099 & 12971 & 11804 & Manual video analysis \\
\hline Strudwick and Reilly ${ }^{13}$ & English professionals (M) & 24 & 11264 & 11433 & 10650 & 12075 & & Manual video analysis \\
\hline \multirow[t]{2}{*}{ Thatcher and Batterham ${ }^{57}$} & English Professionals (M) & 12 & 10274 & & & & & Manual video analysis \\
\hline & U/19 Professionals (M) & 12 & 9741 & & & & & \\
\hline Zubiglia et al., ${ }^{74}$ & Champions League matches (M) & 18 & 10461 & & & & & Automatic tracking on video \\
\hline
\end{tabular}

* Combined results for central and external midfield players

\# Results did not distinguish between fullbacks and central defenders

$\sim$ Results for each playing position were calculated from a combination of data obtained for both groups of players 
Table III. Comparison of distances covered by elite soccer players during the first and second halves of competitive match-play.

\begin{tabular}{|c|c|c|c|c|c|}
\hline Study & Nationality & Total Distance run (m) & 1st Half $(\mathrm{m})$ & 2nd Half (m) & Difference $(\%)$ \\
\hline Barros et al., ${ }^{25}$ & Brazilian & 10012 & 5173 & 4808 & $-7,1$ \\
\hline Burgess et al., ${ }^{30}$ & Australian & 10100 & 5300 & 4800 & $-9,4$ \\
\hline Di Salvo et al., ${ }^{34}$ & European & 11393 & 5709 & 5684 & $-0,4$ \\
\hline Miyagi et al., ${ }^{29}$ & Japanese & 10460 & 5315 & 5141 & $-3,3$ \\
\hline \multirow[t]{2}{*}{ Mohr et al., } & Italian & 10860 & 5510 & 5350 & $-2,9$ \\
\hline & Danish & 10330 & 5200 & 5130 & $-1,3$ \\
\hline Rienzi et al., ${ }^{62}$ & South America/English & 9020 & 4605 & 4415 & $-4,1$ \\
\hline \multirow[t]{2}{*}{ Zubiglia et al., ${ }^{74}$} & English & 10549 & 5297 & 5252 & $-0,9$ \\
\hline & Spanish & 10339 & 5121 & 5218 & $+1,9$ \\
\hline
\end{tabular}

Figure I. An example of a T-pattern incorporating regularity of movements by a centreforward in a F.A. Premiership match.
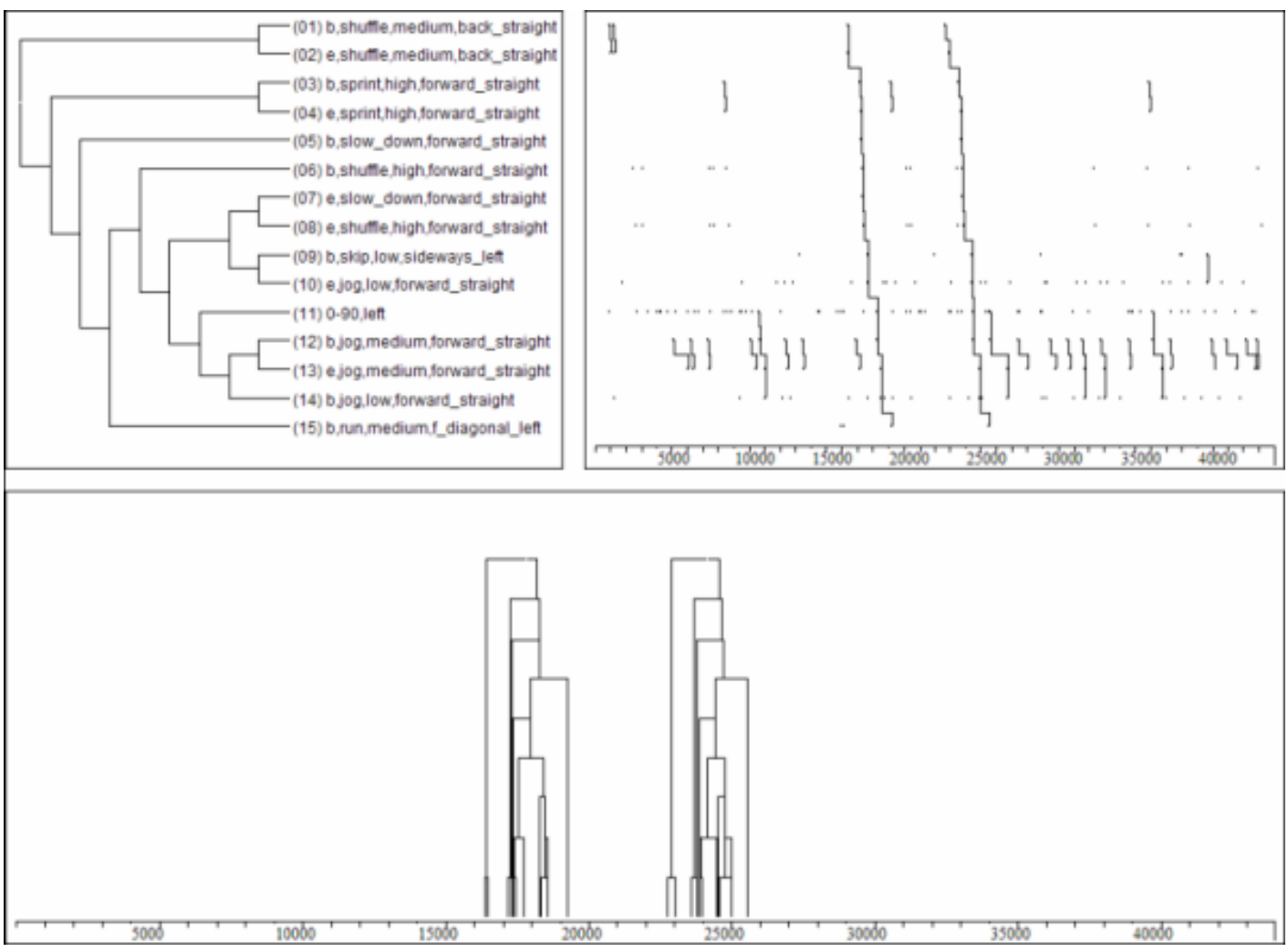